\title{
Diffusion Flux Driven Critical Path Formation as an Order Parameter in Disordered Heterogeneous Ceramic Conductors (HCCs)
}

\author{
Reifsnider $\mathrm{K}^{*}$ \\ Department of Materials Engineering Science, UTARI Texas, USA
}

Submission: June 01, 2017; Published: June 232017

*Corresponding author: Reifsnider K, Department of Materials Engineering Science, University of Texas Arlington Research Institute, Arlington, TX 76019 UTARI, Texas, USA, Tel: 817-272-5904; Email: kenneth.reifsnider@uta.edu

\begin{abstract}
Order parameters are essential in the discussion and analysis of morphology changes in heterogeneous materials as a foundation for understanding and predicting microstructure evolution due to applied fields. While many such parameters have been defined for order-todisorder phenomena, parameters for disorder-to-order behavior are not widely discussed. The present paper suggests that a newly defined "critical path" concept provides a possible order parameter for diffusive flux driven disorder to order morphology changes in Heterogeneous Ceramic Conductors (HCCs).
\end{abstract}

Keywords: HCIC membranes; Electronic conductors; Ionic species

\section{Heterogeneous Ceramic Conductors}

The dense ceramic heterogeneous functional materials and Mixed Ionic and Electronic Conductors (MIECs) used in batteries, fuel cells, separation membranes, countless electronic components and waste storage materials have achieved remarkable functional capabilities including very high ionic species conduction and diffusive transport capabilities. While the conceptual design of such Heterogeneous Ceramic Conductors (HCCs) has been growing rapidly, the understanding of the microstructure evolution driven by the high diffusive flux required to achieve their functional behavior is at a very early stage. For example, it is well established that voids develop in solid ceramic membranes near the material constituent boundaries during extended periods of operation in the presence of electrical and/ or electrochemical potential fields. Unlike the well-known Kirk end all behavior in metals where simple diffusion rate differences at the local level drive the process, the HCC void structures are driven by the external applied fields and the resulting throughthickness high flux of ionic species, and may depend on an array of physical flux species, mobilities, conduction, and dielectric behavior [1-3]. The effect of distributed voids on properties and performance is classically proportional to their volume fraction, but when a void structure is formed, precipitous property and performance changes can occur, often leading to

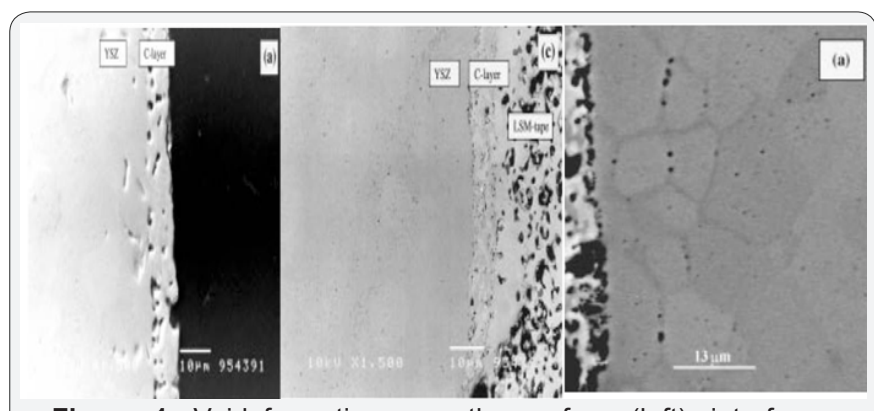

Figure 1: Void formation near the surface (left), interfaces (center) and grain boundaries (right) of heterogeneous electrodes in SOFC during long-term operation (after Mogensen and Jorgesen ).

radical functional and mechanical failure. How that happens is not generally understood, but our recent work suggests a new "critical path" foundation for that science. Flux Driven Morphology Changes: One example of diffusive flux driven morphology changes is shown in Figure 1, where in the diffusion of Oxygen ions through ceramic electrodes leaves a high concentration of vacancies near the surface where electrochemical reactions occur. In addition, the right hand panel of Figure 1 also shows a clear example of void formation at grain boundaries driven by ion flux through that electrode. Eventually, this porosity (individually or in some combination) can lead to gas permeability by transport; for example, "leak flow" through 
the crystal grains may occur. In fact, when surface defects are present, it is possible for the internal porosity to create leakage paths that link to surface details and damage to cause functional or physical failure [4-6].

\section{Critical Path as an Order parameter}

Recently the authors have published a paper based on their work over the last ten years or so which postulates that "Critical Path-Driven Property and Performance Transitions in Heterogeneous Microstructures" can be rationalized by physical observations and conformal multi physics analysis (set on actual microstructures). The hypothesis is that the progressive formation of critical paths (e.g., open void structures in HCIC membranes) is a mechanism that can be used to predict (and avoid or exploit) the sudden changes in properties and performance that accompany flux-driven structure transitions in HFC materials. As a foundation for this work, we have learned how to set (and validate) multi physics models on the actual rendered morphology of the heterogeneous HFCs to predict their properties and performance in the presence of through-thickness flux. For example, we have demonstrated our ability to predict the flux of oxygen through MIECs with different microstructures and phase-fractions as a function of temperature. Figure 2 shows an example of a conformal rendering and our accompanying predictions of oxygen flux for a GDC-CFO membrane with a $60 \%$ GDC- $40 \%$ CFO mixture ratio. The flux paths in Figure 2 show the diffusive mass release of stored material driven by the concentration gradient between the interior (high) and the external surfaces (low) [7-9] (Figure 3).

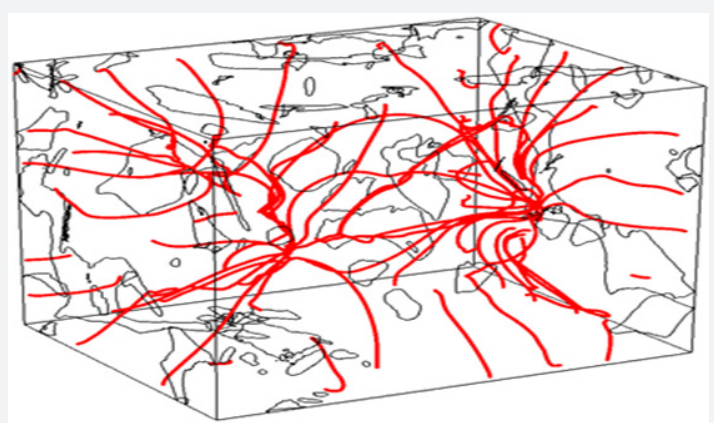

Figure 2: Calculated flux paths of Cs ions from the bulk center toward the boundaries through a holl and it waste form structure.

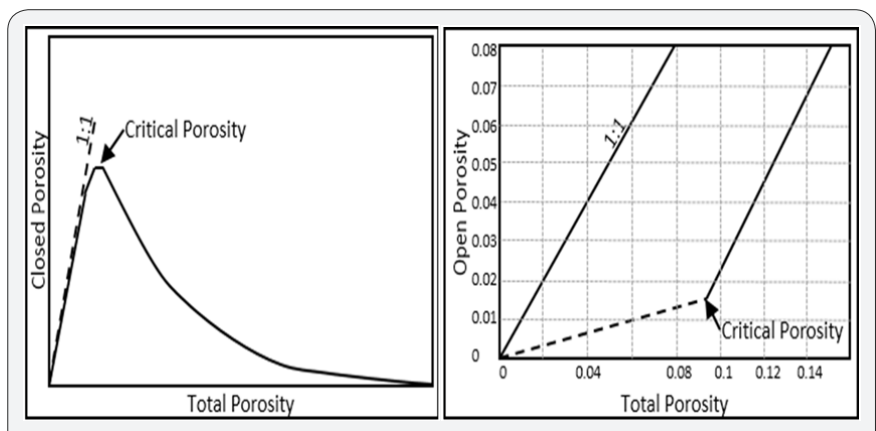

Figure 3: (a) Closed vs. total porosity in a solid identifying emergence of critical porosity, (b) accelerated growth rate of open porosity in ceramic waste forms after threshold.

\section{References}

1. Mogensen M (1996) Performance/structure correlation for composite SOFC cathodes. J Power Sources 173-181.

2. Jørgensen MJ, Holtappels P (2000) Durability test of SOFC cathodes. Journal of Applied Electrochemistry 30(4): 411-418.

3. Kusakabe K, Yoneshige S, Murata A, Morooka S (1997) Gas Permeability of Silicalite membranes Formed on Alpha-Alumina Support Tubes. J Electrochemical Society Proceedings, pp. 95-24.

4. Haas GA, Gray HF, Thomas RE, Pankey T (1977) The role of ceramic voids and fracture propagation in shelf life failure of tubes. IEEE Transactions on Electron Devices 24(1): 62-66.

5. Kenneth R, Fazle R, Vamsee V, Rassel R, Kyle B (2017) Critical pathdriven property and performance transitions in heterogeneous microstructures, J Mater Sci 52(9): 4796-4809.

6. Fazle R, Kyle B, Jake A, Kenneth R (2016) Finite Element analysis of ion transport in Solid State Nuclear Waste Form Materials. JNM, pp. 334.

7. Brinkman F, Reifsnider K (2016) Heterogeneous Materials Design for Sustainable Nuclear Waste Storage Using Life Prediction by Conformal Finite Element Analysis. In: Kirchain RE, Blanpain B, et al. (Eds), John Wiley \& Sons Inc Hoboken, NJ, USA, pp. 203-208.

8. Shaw HF (1998) Determination of the open and closed porosity in an immobilized Pu ceramic waste form (No. UCRL-ID-132605). UCRLID-132605, Lawrence Livermore National Laboratory, Livermore, California.

9. Cao Y, Shjen J, Randall C, Chen LQ (2016) Effect of multi-domain structure on ionic transport, electrostatics, and current evolution in $\mathrm{BaTiO}_{3}$ ferroelectric capacitor. Acta Materialia 112 (2016): 224-230.

Your next submission with Juniper Publishers
will reach you the below assets
- Quality Editorial service
- Swift Peer Review
- Reprints availability
- E-prints Service
- Manuscript Podcast for convenient understanding
- Global attainment for your research
- Manuscript accessibility in different formats
( Pdf, E-pub, Full Text, Audio)
- Unceasing customer service
Track the below URL for one-step submission
https://juniperpublishers.com/online-submission.php

